\title{
FERDINAND RITTER VON ARLT (Obergraupen, 1812 - Viena, 1887)
}

\author{
NOGUERA-PALAU JJ ${ }^{1}$
}

Arlt, oftalmólogo austriaco, nació el 18 de abril de 1812 Obergraupen, cerca de Teplitz en la zona germanófona de Bohemia, en el seno de una familia muy humilde y estudió la carrera de medicina en la universidad de Praga. Graduado en 1839, fue discípulo y ayudante de Johann Nepomuk Fischer, entonces profesor de oftalmología en aquella universidad. De 1846 a 1849 fue profesor suplente de oftalmología en la misma universidad de Praga, y desde agosto de 1849 a julio de 1856 fue nombrado profesor titular. Después fue profesor de oftalmología en la universidad de Viena hasta julio de 1883, momento en que, por su edad, fue jubilado de la actividad docente. Hasta 1887 siguió escribiendo y dedicándose al ejercicio privado de la oftalmología.

La relación de sus publicaciones es inmensa y variada, y casi todas ellas con notable influencia en la oftalmología clínica y quirúrgica de su época. En 1846, en Cuidado de los ojos sanos y enfermos con un anexo sobre las gafas, advertía a toda la comunidad médica de la importancia de tener su propia y personal corrección óptica hecha por oftalmólogos y no dejar tan importante cuestión en manos de los ópticos. Informe de la clínica oftalmológica de la universidad de Viena 1863-1865 con la colaboración del Prof. Dr. Ferdinand Arlt, editado por los doctores Max Tetzer, Lucian Rydel y Otto Becker (1867). Entre 1851 y 1856 escribió el tratado Enfermedades de los ojos en tres volúmenes. Lesiones oculares (1875) fue traducido al francés en 1877 y al inglés en 1878. Sobre el origen y las causas de la miopía (1876), La miopía, origen y causas (1878); en 1854 ya había expuesto el alargamiento del ojo como condición anatómica de este defecto de refracción. Semiología de las enfermedades de la conjuntiva, córnea, piel, iris y cuerpo ciliar (1881). Semiología de las enfermedades de los ojos (1881), traducida al inglés en 1885. Lecciones sobre el glaucoma (1884).
Lecciones de cirugía (1874), en el «Tratado general de oftalmología» de Alfred Carl Graefe (primo de Albrecht von Graefe) y Edward Theodor Saemisch. En 1855, con Frans Cornelis Donders, fue editor adjunto de Archiv für Ophthalmologie, publicación fundada un año antes por Albrecht von Graefe.

Como docente, fue universalmente reconocido por la riqueza de sus disertaciones. Entre sus discípulos hay que citar a A. von Graefe, Otto Becker, Wilhelm Schulek, Huber Sattler, Otto Bergmeister, Ernst Fuchs, Friedrich Dimmer... y a Isabel Hayes Chapin Barrows, la primera mujer que ejerció la

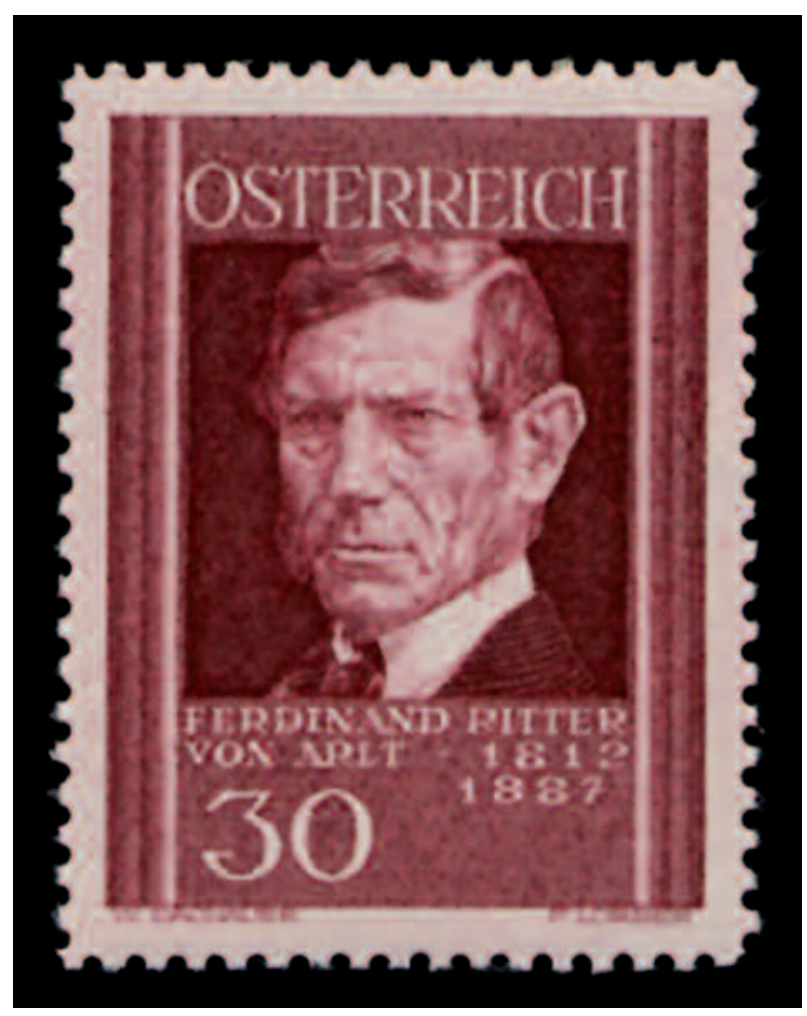

Austria, 1937 / Yvert 511 de 506/14.

\footnotetext{
1 Oftalmólogo. Pamplona.

E-mail: jnoguera72b@terra.es
} 
oftalmología en los Estados Unidos y cuya primera operación de cataratas la hizo con Eduard Jaeger.

Falleció en Viena, víctima de una gangrena senil, el siete de marzo de 1887.

Los correos de la primera república de Austria emitieron en 1937 los sellos 506/14 dedicados a nueve médicos de aquel país: Gerhard Freiherr van
Swieten (1700-1772), Leopold Auenbrugger [von Auenbrugg] (1722-1809), Karl Freiherr von Rokitansky (1804-1878), Joseph Skoda (1805-1881), Ferdinand Ritter von Hebra (1816-1880), Ferdinand Ritter von Arlt (1812-1887), Joseph Hyrlt (1810-1894), Theodor Billroth (1829-1894) y Theodor Meynert (1833-1892). 